\title{
A self-feeding system for pre-weanling mice'
}

Some preliminary results of a current research project involving the search for a reliable, low-risk self-feeding system for preweanling mice is described. The implications and advantages in future research with such animals is discussed with regard to studies of the effects of early experience on adult patterns of behavior.

The importance of early experience for the development of adaptive adult patterns of behavior is currently receiving considerable emphasis in psychological research. The rapidly accumulating evidence in animal research involving environmental enrichment or deprivation paradigms seems to indicate that more or less dramatic effects are observed in adult behavioral patterns following the independent variable treatment (Fiske \& Maddi, 1961; Harlow \& Zimmerman, 1959; Haywood \& Tapp, in press). Further, the evidence seems to suggest that the effects of early experience differ as a function of pre- or post-weaning stage of development of the organism (Fiske \& Maddi, 1961; Levine, 1956; Levine, 1958; Levine \& Otis, 1958; Mogenson \& Ehrlich, 1958). Generally, these and other studies lead us to suspect that post-weaning stimulation affects later problem-solving behavior, while preweaning stimulation affects primarily emotional patterns in the adult organism.

Although the importance of early experience in the development of the organism is a certainty, we should, perhaps, entertain somewhat more caution in the interpretation of the results obtained than has been the custom within the context of these and similar infraprimate studies. Aside from the fact that the identification of the parameters of early experience has not been systematically investigated, there remains in preweaning stimulation studies with rats and mice, a crucial variable which has been uncontrolled and unmentioned in the interpretation of the results.

This variable is the effect of "mothering" specifically, and the effects of parity, in general. That is to say, it is perhaps difficult for some to believe that handling an animal for a few minutes a day, for example, in and of itself can result in such behavior changes as are reported. In pre-weanling animals, a considerable degree of mothering activity is directed to an offspring upon its return to the home cage (sniffing, licking, nudging, etc.).Such activity is typically more intense than "normal," both quantitatively and qualitatively. Yet any possible influence of this activity remains unexplored-and for good reason. It is somewhat difficult to take rats and mice away from their mothers at a pre-weanling stage of development and keep them alive by means other than force feeding. This latter technique, successful with the Lobund group (Pleasants, 1959), is less desirable than a system which would require no special handling or stimulation by the experimenter. Such a self-feeding system would permit ultimate control and precision in future studies of early experience effects, and would allow much more definitive kinds of research with these animals than have been possible to date. I would like to report, therefore, some preliminary results of an exploratory effort currently being carried on by the writer in a search for a reliable, low-mortality selffeeding system with $\mathrm{BALB} / \mathrm{C}$ and $\mathrm{C} 57 \mathrm{BL}$ mice.

pleasants (1959), at the Lobund Institute, has reported in detail the technique involved in rearing germfree animals through the weaning stage of development. These animals are force-fed a complex milk formula which is chemically and nutritionally similar in composition to the mother's natural milk.

Following a predetermined feeding regimen, the Lobund group has successfully reared these animals by hand-feeding up to 15 days of age, at which time mice, in this instance, are able to feed themselves from small dishes containing the milk formula along with other dishes of water and solid food. Pleasants also reports that perineal stimulation of infant mice is necessary up to day 15 in order to maintain adequate defecation and urination. Apparently, this stimulation is performed by the mother under normal conditions, and if the infant doesn't receive this stimulation, elimination difficulties arise, endangering the life of the animal.

In an attempt to devise a self-feeding system, one BALB/C "pilot mouse" was reared in a small plastic container. The animal was taken from its home cage at age 11 days and fully weaned at 18 days of age. Inasmuch as the complex milk formula used by the Lobund group was more or less difficult to obtain, the animal was given a commercial brand of baby formula, Similac With Iron. This was diluted with equal parts of water and force-fed with an eye dropper approximately every $2 \mathrm{hr}$. from $7 \mathrm{~A} . \mathrm{M}$. to 12 midnight daily. The animal was not fed between midnight and $7 \mathrm{~A}, \mathrm{M}$. This regimen was continued until age 15 days, when the animal was able to maintain its food intake from a small milk dish. The milk diet was supplemented with small pieces of bread. Although there was an initial drop in weight, this animal survived on the commercial milk formula with relatively little difficulty, and is completely healthy at this writing (age 60 days). The animal was stimulated perineally with a piece of cloth, but nevertheless displayed difficulties in defecation. 
The milk formula was diluted with water slightly more than the $50 \%$ ratio initially used. This mixture solved the elimination problem. At 18 days of age, the animal was placed in a standard cage with a diet of commercial food pellets and presented no further health problems. Having discovered that the complex milk formula was not necessary to rear pre-weanling animals, a group of eight C57 BL mice were selected for preliminary investigation of a self-feeding system.

The animals were placed in separate translucent plastic boxes $(3-1 / 2$ in. $x 4$ in.), the floor of which was covered with corduroy cloth. The animals were 10 days old at separation, and the eyes and ears of most of them were not yet fully opened. The plastic boxes were equipped with plastic I.V.tubing of $0.04 \mathrm{~mm}$ inner diameter. The tubing was affixed to plastic, disposable syringes filled with the milk formula, in the hope that the animals would suck the milk from the tubes. This system was abandoned rather quickly when it became apparent that the animals failed to feed from the tubes. Within $24 \mathrm{hr}$., small dishes of milk were glued to the floor of the boxes and filled with milk, along with small pieces of water-saturated bread. The dishes were filled with fresh milk at regular intervals before souring occurred. At 15 days of age, the milk and bread was replaced with wet mash of a high water content. At 16 days of age, dry food pellets, water, and sunflower seeds were placed in the boxes.

The animals failed to maintain an intake of food adequate in quantity for steady growth over the first week, although large individual differences were observed. Weight loss occurred despite the fact that the animals "knew" where the food dish was. Most of the animals became mildly diarrhetic during the first week contributing to their progressively weakening condition. At 18 days of age, five of the animals died overnight.

The three remaining animals survived, were weaned fully at 19 days, and appear to be healthy at this time (age 45 days). These animals have never been handled during their life span, have received less than 10 days of mothering, and now offer some unique opportunities for further research in spite of the small number.

Despite the obvious crudity of the self-feeding system described, approximately $38 \%$ of the animals did survive. Insofar as the BALB/C strain of mice is generally heartiers it can be expected that the mortality rate will decrease by using this strain. The task remains to make the system much less traumatic for the animals involved. These results, combined with a search for a more efficient, sophisticated system, will very likely result in highly satisfactory results. Once a better system is found, pre-weanling mice and rats can be taken away from their mothers at even earlier ages, thus offering a degree of environmental control, free from the confounding variables of home cage events and handling, hereto unknown in studies of infraprimate organisms. This in turn will permit a great deal more analytical precision in studies dealing with early experiential effects.

\section{References}

Denenberg, V. H., \& Morton, J. R. C. Effects of environmental complexity and social groupings upon modification of emotional behavior. J. comp. physiol. Psychol., 1962, 55, 242-246.

Fiske, D. W., \& Maddi, S. R. Functions of varied experience. Homewood: Dorsey, 1961.

Harlow, H. F., \& Zimmerman, R. R. Affectional responses in the infant monkey. Science, 1959, 130, 421-432.

Haywood, H. C., \& Tapp, J. T. Experience and the development of adaptive behavior. In $\mathrm{E}$. $\mathrm{R}$. Ellis (Ed.), International review of research in mental retardation. New York: Academic Press, in press.

Levine, S. A further study of infantile handling and adult avoidance learning. $J$. Pers., 1956, 25, 70-80.

Levine, S., \& Otis, L. S. The effects of handling before and after weaning on the resistance of albino rats to later deprivation. Canad. J. Psychol., 1958, 12, 103-108.

Mogenson, G. J., \& Ehrlich, D. J. The effects of early gentling and shock on growth and behavior in rats. Canad. J. Psychol., $1958,12,165-170$.

Pleasants, J. R. Rearing germfree Caesarean-born rats, mice, and rabbits through weaning. Annals New York Acad. Sci., 1959, 78 116-126.

\section{Note}

1. The author wishes to acknowledge the invaluable contributions and suggestions of Dr. Gilbert W. Meier in carrying out this project. 